Tropical Journal of Pharmaceutical Research February 2018; 17 (2): 239-244

ISSN: $1596-5996$ (print); 1596-9827 (electronic)

(C) Pharmacotherapy Group, Faculty of Pharmacy, University of Benin, Benin City, 300001 Nigeria.

Available online at http://www.tjpr.org

Original Research Article

http://dx.doi.org/10.4314/tjpr.v17i2.7

\title{
Evaluation of the diuretic potentials of naringenin in hypercholesterolemic rats
}

\author{
Mohd N Ansari ${ }^{1 *}$, Majid A Ganaie ${ }^{1}$, Tajdar H Khan ${ }^{2}$, Abdul Samad ${ }^{2}$, Hassan A \\ Madkhali ${ }^{1}$, Syed Rizwan Ahamad ${ }^{3}$ \\ ${ }^{1}$ Department of Pharmacology, ${ }^{2}$ Department of Pharmaceutical Chemistry, College of Pharmacy, Prince Sattam bin Abdulaziz \\ University, Al-Kharj, ${ }^{3}$ Central Laboratory, Research Center, College of Pharmacy, King Saud University, Riyadh, Saudi Arabia
}

*For correspondence: Email: m.ansari@psau.edu.sa; Tel: +966-11-5886037

\begin{abstract}
Purpose: To investigate the diuretic potentials of naringenin (NGN) in obesity induced in rats by high fat $\operatorname{diet}(H F D)$.

Methods: To prepare HFD, normal pellet diet was crushed and thoroughly mixed with cholesterol powder $(1 \% \mathrm{w} / \mathrm{w})$. The mixture was mixed with some water and made into pellets which were then oven-baked to dry. Four groups of male Wistar albino rats $(n=6)$ were used for the study. Normal control (group I) received normal pellet diet. Group 2 (HFD-only) was fed HFD for 28 days, while Groups 3 and 4 were co-administered HFD and NGN at doses of 50 and $100 \mathrm{mg} / \mathrm{kg}$, respectively. All treatments were given orally, and lasted for 28 days. Twenty-four hours after the last dose of NGN, blood was collected from all rats and total cholesterol levels determined to confirm obesity. Thereafter, the rats were placed in metabolic cages and urine samples were collected at two time-points (5 and 24 h) for measurement of urine volume, urinary $\mathrm{pH}$, conductivity and electrolyte levels ( $\mathrm{Na}, \mathrm{K}$ and $\mathrm{Cl})$.

Results: Treatment with HFD resulted in significantly $(p<0.05)$ increased serum cholesterol level $(178.83 \pm 5.43 \mathrm{mg} / \mathrm{dL})$ when compared to normal control rats $(88.17 \pm 4.04 \mathrm{mg} / \mathrm{dL})$. It also led to decrease in urinary volume ( 50\%) at both time points (5 and $24 \mathrm{~h})$ and in excretion of urinary electrolytes (sodium, potassium and chloride ions). However, the changes in these parameters were significantly reversed by NGN administration ( $p<0.05)$.

Conclusion: These results demonstrate the diuretic activity of NGN in HFD-induced obese rats. Thus, NGN can be further explored for use in combination with hypolipidemic agents to tackle obesity.
\end{abstract}

Keywords: High-fat diet, Hypercholesterolemia, Naringenin, Obesity

\begin{abstract}
This is an Open Access article that uses a funding model which does not charge readers or their institutions for access and distributed under the terms of the Creative Commons Attribution License (http://creativecommons.org/licenses/by/4.0) and the Budapest Open Access Initiative (http://www.budapestopenaccessinitiative.org/read), which permit unrestricted use, distribution, and reproduction in any medium, provided the original work is properly credited.
\end{abstract}

Tropical Journal of Pharmaceutical Research is indexed by Science Citation Index (SciSearch), Scopus, International Pharmaceutical Abstract, Chemical Abstracts, Embase, Index Copernicus, EBSCO, African Index Medicus, JournalSeek, Journal Citation Reports/Science Edition, Directory of Open Access Journals (DOAJ), African Journal Online, Bioline International, Open-J-Gate and Pharmacy Abstracts

\section{INTRODUCTION}

Epidemiologic data have shown that Westernstyle dietary patterns play a major role in the development of diabetes mellitus, hyperlipidemia and disorders of the cardiovascular system $[1,2]$.
Studies have demonstrated a link between HFD and the etiology of hypertension, obesity and hyperlipidemia [3]. There are high chances of acute renal dysfunction from fluid shifts and hypovolemia in obese patients with BMI more than $60 \mathrm{~kg} / \mathrm{m}^{2}$. In addition, obesity is associated 
with significant decreases in urine output. Many types of drugs have been effectively used for the treatment of these clinical disorders, but the unwanted side effects of these agents limit their applications. The established lipid lowering drugs such as fibrates, statins and bile acid-binding resins have many side effects [4]. Therefore, there is a growing interest in the development of lipid-lowering drugs with diuretic activities from natural products for the treatment of obesity.

Daily intake of fruits and vegetables could be beneficial in the treatment of chronic diseases that make up metabolic syndrome $[5,6]$. Several studies have demonstrated the potential health benefits of flavonoids and anthocyanins against the various disorders associated with metabolic syndrome [7]. Citrus fruits are rich in flavonoids, the most predominant of which is naringenin (4', 5, 7-trihydroxyflavanone; NGN), a flavanone [8]. Studies have demonstrated that NGN possesses anticancer [9], lipid-lowering [10], antiatherogenic [11] and antioxidant [12] properties.

The aim of the present study was to investigate the diuretic effect of NGN on HFD-induced obesity in Wistar albino rats.

\section{EXPERIMENTAL}

\section{Reagents and chemicals}

Naringenin powder and total cholesterol kit were products of Sigma-Aldrich Chemical Co., USA. The NGN doses used in this study were based on a previous investigation carried out [13].

\section{Animals}

Mature, male albino rats (Wistar strain) weighing 180-200g were supplied by the Animal Care Unit of College of Pharmacy, Prince Sattam bin Abdulaziz University, KSA. The rats were acclimatized for 7 days under standard laboratory conditions in an environment with $12 \mathrm{~h}$ light/12h dark cycle Standard pellet diet and water were made available to the rats ad libitum. The study was approved by the Ethical Review Committee, College of Pharmacy, Prince Sattam Bin Abdulaziz University, KSA (approval ref no. HAP-01-KJ-050). The experimental procedures were performed according to the guiding principles of the Institute for Laboratory Animal Research in Guide for the Care and Use of Laboratory Animals [14].

\section{Preparation of cholesterol-supplemented diet}

Normal pellet diet was ground and mixed thoroughly with cholesterol powder $(1 \% \mathrm{w} / \mathrm{w})$.
The resultant mixture was mixed with water and made into pellets which were then oven-baked for proper drying to avoid fungal contamination.

\section{Induction of obesity}

Normal Wistar rats were fed with the mixed pellet diet containing $1 \%$ cholesterol (HFD) for 28 days.

\section{Diuretic activity}

Four groups of Wistar albino rats were used (6 rats per group). The assignment of rats to groups was done randomly. Rats in group 1 (normal control) received normal pellet diet only, while group 2 rats were fed HFD only. Groups 3 and 4 were fed HFD co-administered with NGN at doses of 50 and $100 \mathrm{mg} / \mathrm{kg}$, respectively. All treatments lasted for 28 days. Twenty-four hours after the last NGN dose, blood was withdrawn from retro-orbital plexus for the estimation of serum cholesterol level. Subsequently, urine samples were collected at two time points (5 and $24 \mathrm{~h}$ ) from the rats put in metabolism cages for $24 \mathrm{~h}$. The $24 \mathrm{~h}$ urine samples were filtered at the time of urine collection and used for determination of urinary $\mathrm{pH}$ and conductivity. The remaining urine samples were stored at $-20{ }^{\circ} \mathrm{C}$ and used for analyses of electrolytes $\left(\mathrm{Na}^{+}, \mathrm{K}^{+}\right.$ and $\mathrm{Cl}^{-}$).

\section{Evaluation of urine parameters}

Urinary conductivity was determined using Jenway conductivity meter (Jenway, UK), while urinary $\mathrm{pH}$ was measured using a $\mathrm{pH}$ meter (Hanna Instruments, Lynnfield, MA). The $24 \mathrm{~h}$ samples were then diluted (1:1000 in deionized water) and evaluated levels of $\mathrm{K}^{+}, \mathrm{Na}^{+}$and $\mathrm{Cl}^{-}$ using Professional Ion Chromatography (Metrohm, Switzerland).

Determination of saluretic activity, natriuretic activity and carbonic anhydrase inhibitory (CAl) activity

Saluretic activity was measured by simply summing up the concentrations of $\mathrm{Na}^{+}$and $\mathrm{K}^{+}$ present in the urine samples of each group. Natriuretic activity was measured by calculating the ratio of $\mathrm{Na}^{+}$and $\mathrm{K}^{+}$ion concentrations in the urine samples, while CAI activity was estimated by calculating the ratio: $\mathrm{Cl}^{-} /\left(\mathrm{Na}^{+}+\mathrm{K}^{+}\right)[15]$.

\section{Statistical analysis}

Data are expressed as mean \pm SEM, and were analyzed by one-way ANOVA, followed by Dunnett's post hoc test for determination of intergroup variability using SPSS program (version 21 
software package; SPSS Inc, USA). Values of $p$ $<0.05$ were taken as indicative of statistically significant differences.

\section{RESULTS}

\section{Effect of NGN on serum total cholesterol levels}

After feeding normal healthy rats with HFD, there were significant increases in serum total cholesterol levels in all the rats $(p<0.05)$. However, the HFD-induced increases in serum total cholesterol in the obese rats were significantly decreased $(p<0.05)$ by NGN treatment (Figure 1).

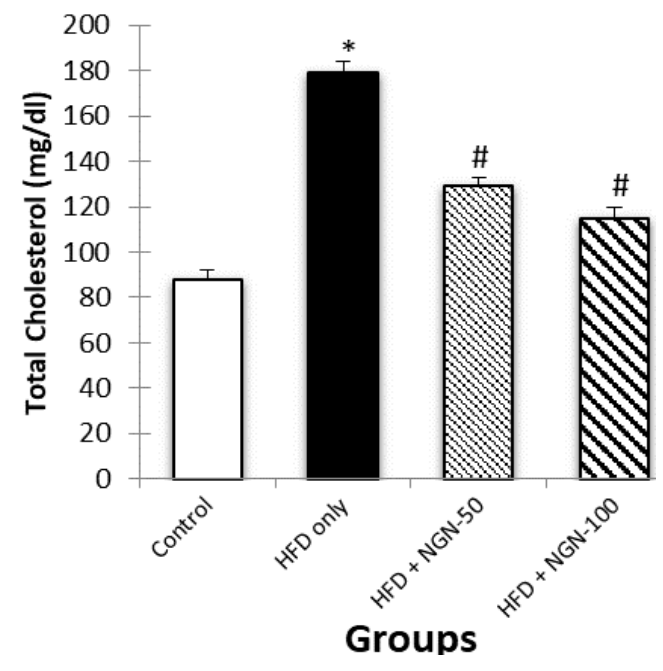

Figure 1: Total cholesterol level $(\mathrm{mg} / \mathrm{dL})$ of rats with HFD-induced experimental obesity. Values represent mean \pm SEM of six rats for each group; ${ }^{*} p<0.05$, relative to control group $(\mathrm{n}=6) ;{ }^{\#} p<0.05$, relative to HFD-only group

\section{Effect of NGN on urine output and diuretic activity}

The results of urine volume analysis are presented in Table 1. Obesity induced by HFD resulted in significant decreases in urine volume at both time points of sample collection i.e. $5 \mathrm{~h}$ and $24 \mathrm{~h}$, relative to normal control $(p<0.05)$. Treatment with NGN at doses of 50 and 100 $\mathrm{mg} / \mathrm{kg}$ resulted in significant increases in urine volume, when compared to the obese rats, showing the diuretic effect of NGN.

\section{Effect of NGN on urinary pH and conductivity}

Results of urinary $\mathrm{pH}$ and conductivity are presented in Table 2. There was a decrease in the urinary $\mathrm{pH}$ of the obese rats (HFD only) when compared to urinary $\mathrm{pH}$ of control rats. However, NGN treatment resulted in increased urinary $\mathrm{pH}$, although the increases were not statistically significant. The conductivity of the urine samples from the obese rats was significantly decreased, but was significantly increased by NGN treatment at the two dose levels.

Table 1: Effect of NGN on urine volume and diuretic index in normal and obese rats

\begin{tabular}{|c|c|c|c|c|}
\hline \multirow[t]{2}{*}{ Group } & \multicolumn{2}{|c|}{ At 5h } & \multicolumn{2}{|c|}{ At 24h } \\
\hline & $\begin{array}{l}\text { Urine } \\
\text { volume } \\
(m L)\end{array}$ & $\begin{array}{c}\text { Diuretic } \\
\text { index }\end{array}$ & $\begin{array}{c}\text { Urine } \\
\text { volume } \\
(\mathrm{mL})\end{array}$ & $\begin{array}{c}\text { Diuretic } \\
\text { index }\end{array}$ \\
\hline CON & $1.04 \pm 0.10$ & 1.00 & $6.74 \pm 0.41$ & 1.00 \\
\hline $\begin{array}{l}\text { HFD } \\
\text { only }\end{array}$ & $0.56 \pm 0.04^{*}$ & 0.54 & $3.44 \pm 0.31^{*}$ & 0.51 \\
\hline $\begin{array}{l}\text { HFD + } \\
\text { NGN } \\
(50 \\
\mathrm{mg} / \mathrm{kg})\end{array}$ & $1.90 \pm 0.11^{\#}$ & 1.83 & $11.52 \pm 0.65^{\#}$ & 1.71 \\
\hline $\begin{array}{l}\text { HFD + } \\
\text { NGN } \\
(100 \\
\mathrm{mg} / \mathrm{kg}) \\
\end{array}$ & $2.28 \pm 0.17^{\#}$ & 2.19 & $16.12 \pm 1.09^{\#}$ & 2.39 \\
\hline $\begin{array}{l}\text { Values } \\
\text { excretic } \\
\text { *Signifi } \\
\text { group } \\
\text { compar }\end{array}$ & $\begin{array}{l}\text { represent } \\
\mathrm{n} \text { in test g } \\
\text { antly differ } \\
(p<0.05 \\
\text { ed with HFD }\end{array}$ & when & $\begin{array}{l}\text { M }(\mathrm{n}=6) \text {. } \\
\text { tion in cont } \\
\text { ompared wi } \\
\text { antly differe } \\
(p<0.05)\end{array}$ & $\begin{array}{l}\text { Index = } \\
\text { group. } \\
\text { control } \\
\text { when }\end{array}$ \\
\hline
\end{tabular}

Table 2: Effect of NGN on urinary $\mathrm{pH}$ and conductivity in normal and obese rats

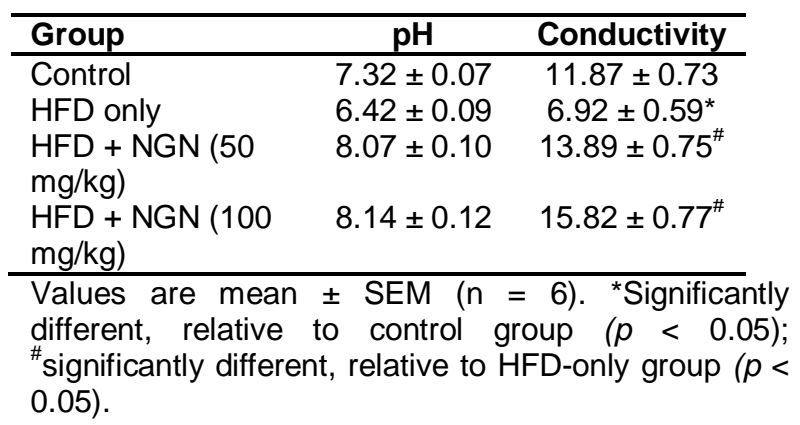

\section{Effect of NGN on urinary electrolyte excretion}

Table 3 shows the urinary electrolyte content of the HFD-only, NGN-treated (50 and $100 \mathrm{mg} / \mathrm{kg}$ ) and control rats. Excretion of urinary electrolytes $\left(\mathrm{Na}^{+}, \mathrm{K}^{+}\right.$and $\left.\mathrm{Cl}^{-}\right)$was significantly lowered in the obese rats after exposure to HFD, when compared to control rats. The two doses of NGN (50 and $100 \mathrm{mg} / \mathrm{kg}$ ) resulted in significant increases in urinary electrolyte excretion, relative to the HFD-only group $(p<0.05)$.

\section{Effect of NGN on natriuretic activity, saluretic activity and CAl activity}

Oral administration of NGN to obese Wistar albino rats at $50 \mathrm{mg} / \mathrm{kg}$ and $100 \mathrm{mg} / \mathrm{kg}$ produced significant saluretic activity, but did not result in 
Table 3: Effect of NGN on urinary electrolyte excretion in normal and obese rats

\begin{tabular}{lcccc}
\hline Parameter & Control & HFD-only & \multicolumn{2}{c}{ HFD + NGN } \\
\cline { 3 - 5 } & & & $\mathbf{5 0 ~} \mathbf{~ g} / \mathbf{k g}$ & $\mathbf{1 0 0} \mathbf{~ m g / k g}$ \\
\hline Urinary $\mathrm{Na}^{+}(\mathrm{mmol} / \mathrm{L})$ & $85.8 \pm 6.35$ & $43.2 \pm 3.21^{*}$ & $99.2 \pm 5.72^{\#}$ & $110.2 \pm 6.67^{\#}$ \\
Urinary $\mathrm{K}^{+}(\mathrm{mmol} / \mathrm{L})$ & $56.8 \pm 3.67$ & $24.4 \pm 2.23^{*}$ & $67.4 \pm 4.35^{\#}$ & $75.6 \pm 3.57^{\#}$ \\
Urinary Cl $(\mathrm{mmol} / \mathrm{L})$ & $61.8 \pm 5.81$ & $31.6 \pm 3.06^{*}$ & $67.8 \pm 4.33^{\#}$ & $77.4 \pm 4.79^{\#}$ \\
$\mathrm{Na}^{+}$index & 1.00 & 0.50 & 1.16 & 1.28 \\
$\mathrm{~K}^{+}$index & 1.00 & 0.43 & 1.19 & 1.33 \\
$\mathrm{Cl}^{-}$index & 1.00 & 0.51 & 1.10 & 1.25 \\
\hline
\end{tabular}

Results are expressed as mean \pm SEM $(n=6)$. Index = excretion in test group / excretion in control group. *Significantly different, relative to control group $(p<0.05)$; " significantly different, relative to HFD-only group ( $p<$ 0.05)

Table 4: Effect of NGN on natriuretic activity, saluretic activity and CAl activities in normal and obese rats

\begin{tabular}{lcccc}
\hline Parameter & Control & HFD-only & \multicolumn{2}{c}{ HFD + NGN } \\
\cline { 3 - 5 } & & & $\mathbf{5 0} \mathbf{~ m g} / \mathbf{~ k g}$ & $\mathbf{1 0 0} \mathbf{~ m g / ~ k g}$ \\
\hline Saluretic activity & $147.6 \pm 8.55$ & $74.8 \pm 3.89^{*}$ & $167.0 \pm 8.15^{\#}$ & $187.6 \pm 8.87^{\#}$ \\
Natriuretic activity & $1.54 \pm 0.14$ & $1.82 \pm 0.16$ & $1.52 \pm 0.15$ & $1.45 \pm 0.04$ \\
CAl activity & $0.44 \pm 0.05$ & $0.49 \pm 0.07$ & $0.41 \pm 0.03$ & $0.42 \pm 0.03$ \\
Saluretic Index & 1.00 & 0.51 & 1.13 & 1.27 \\
Natriuretic Index & 1.00 & 1.18 & 0.99 & 0.94 \\
CAI Index & 1.00 & 1.11 & 0.93 & 0.95 \\
\hline
\end{tabular}

Results are expressed as mean \pm SEM $(n=6)$. Index = excretion in test group / excretion in control group. *Significantly lower, relative to control group $(p<0.05)$; " significantly higher than corresponding value for HFDonly group $(p<0.05)$.

inhibition of carbonic anhydrase activity (Table 4).

\section{DISCUSSION}

The World Health Organization (WHO) has defined obesity is an abnormal accumulation of adipose tissue which is detrimental to good health [16]. Increased lipid levels in blood are important risk factors for atherosclerosis, stroke and hypertension which are major health problems in developing countries. Studies have established an association between obesity and various co-morbidities such as hypertension, diabetes mellitus and dyslipidemia [17]. In the present study, the diuretic and antihypercholesterolemic effect of NGN in HFDinduced experimental obesity in Wistar albino rats was assessed. Obesity was induced by feeding high fat diet for 28 days, and confirmed by an increase in serum total cholesterol.

Studies have indicated that excess intake of high-fat diet is not accompanied by a relative increase in its oxidation, leading to accumulation of more lipids in adipose tissue and an increase in body weight $[18,19]$. This is in agreement with the results obtained in the present study, where feeding of HFD to normal rats led to significant increases in serum cholesterol levels. Furthermore, analyses of urine samples from the rats fed HFD for 28 days revealed significant decreases in urinary volume and significant decreases in excretion of $\mathrm{Na}^{+}, \mathrm{K}^{+}$and $\mathrm{Cl}^{-}$. It has been reported that obesity in rats is associated with some degree of impairment of urinary bladder function through decreased urodynamic pressure without disturbance of glucose metabolism $[20,21]$.

In the present study, oral administration of NGN to obese rats at $50 \mathrm{mg} / \mathrm{kg}$ and $100 \mathrm{mg} / \mathrm{kg}$ for 28 days produced anti-obesity and diuretic effects which were clearly evidenced by significant decreases in serum cholesterol levels and increased urinary volume.

In a previous study, NGN ameliorated increases in plasma lipid levels in HFD-fed rats [22]. Increases in plasma and tissue cholesterol levels of ethanol-fed rats have been attributed to upregulation of HMG CoA reductase, the ratelimiting enzyme in the biosynthetic pathway of cholesterol [23]. Studies have demonstrated the inhibitory effect of NGM $(50 \mathrm{mg} / \mathrm{kg})$ administered along with ethanol, on the activity of HMG CoA reductase [24].

The findings of the present study indicate dosedependent effect of NGN on urine excretion. Diuretic activity is considered to be good if diuretic index value is greater than 1.50, moderate for values between 1.00 and 1.50 , mild if the values lie between 0.72 and 1.00 , and absent if the value is less than 0.72 [25]. In present study, the diuretic index values of the NGN-treated groups (50 and $100 \mathrm{mg} / \mathrm{kg}$ ) were 1.83 and 2.19 (at 5h), and 1.71 and 2.39 (at 
24h), respectively, indicating that NGN exhibited very good diuretic property especially at the higher dose of $100 \mathrm{mg} / \mathrm{kg}$.

In addition, the excretion of $\mathrm{Na}^{+}, \mathrm{K}^{+}$and $\mathrm{Cl}^{-}$in urine of the obese rats treated with NGN was significantly increased, and there was slight alkalization of urine. Increased urinary $\mathrm{Na}^{+}$ excretion in the experimental animals after NGN administration is an indication of the potential of NGN as an antihypertensive agent [26].

Conductivity, an indirect index of urinary ion content, significantly decreased in the obese rats after administration of HFD for 28 days, but significantly increased by NGN treatment.

\section{CONCLUSION}

These results indicate that oral administration of NGN to hypercholesterolemic rats significantly mitigated increases in serum cholesterol, and produced significant diuretic effect. Thus, it can be reasonably suggested that NGN may be useful for the treatment of hypercholesterolemia associated with water and sodium retention. However, this is subject to toxicity and clinical studies.

\section{DECLARATIONS}

\section{Conflict of Interest}

Authors declare that they have no conflict of interest.

\section{Contribution of authors}

We declare that this work was done by the authors named in this article and all liabilities pertaining to claims relating to the content of this article will be borne by the authors. Majid A. Ganaie, and Mohd N. Ansari designed the study. Abdul Samad, Tajdar H. Khan and Hassan A. Madkhali collected and analyzed the data. Mohd N. Ansari and Majid A. Ganaie wrote the manuscript with support of Syed Rizwan Ahamad. All authors read and approved the manuscript for publication.

\section{REFERENCES}

1. Fogli-Cawley JJ, Dwyer JT, Saltzman E, McCullough ML, Troy LM, Meigs JB, Jacques PF. The 2005 Dietary Guidelines for Americans and risk of the metabolic syndrome. Am J Clin Nutr 2007; 86: 1193-1201.

2. Kesse-Guyot E, Fezeu L, Galan P, Hercberg $S$, Czernichow S, Castetbon K. Adherence to French nutritional guidelines is associated with lower risk of metabolic syndrome. J Nutr 2011; 141: 1134-1139.

3. Yang ZH, Miyahara H, Takeo J, Katayama M. Diet high in fat and sucrose induces rapid onset of obesity-related metabolic syndrome partly through rapid response of genes involved in lipogenesis, insulin signalling and inflammation in mice. Diabetol Metab Syndr 2012; 4: 32.

4. Chattopadhyaya $R$, Pathak $D$, Jindal $D P$. Antihyperlipidemic agents. A review. Indian Drugs 1996; 33: 85-97.

5. Liu S, Serdula M, Janket SJ, Cook NR, Sesso HD, Willett WC, Manson JE, Buring JE. A prospective study of fruit and vegetable intake and the risk of type 2 diabetes in women. Diabetes Care 2004; 27: 2993-2996.

6. Estaquio C, Castetbon K, Kesse-Guyot E, Bertrais $S$, Deschamps V, Dauchet L, Péneau S, Galan $P$, Hercberg S. The French National Nutrition and Health Program Score is associated with nutritional status and risk of major chronic diseases. J Nutr 2008; 138: 946953.

7. Martin K, Appel C. Polyphenols as dietary supplements: A double edged sword. Nutr Diab Suppl 2010; 2: 1-12.

8. Tripoli E, Guardia ML, Giammanco $S$, Majo DD, Giammanco M. Citrus flavonoids: molecular structure, biological activity and nutritional properties: a review. Food Chem2007; 104: 466-479.

9. So FV, Guthrie N, Chambers AF. Inhibition of human breast cancer cell proliferation and delay of mammary tumorigenesis by flavonoids and citrus juices. Nutr Cancer 1996; 26: 167-181.

10. Jeon SM, Park YB, Choi MS. Antihypercholesterolaemic property of naringin alters plasma and tissue lipids, cholesterol-regulating enzymes, fecal sterol and tissue morphology in rabbits. Clin Nutr 2004; 23: 1025-1034.

11. Choe SC, Kim HS, Jeong TS, Bok SH, Park YB. Naringin has an antiatherogenic effect with the inhibition of intercellular adhesion molecule-1 in hypercholesterolemic rabbits. J Cardiovasc Pharmacol 2001; 38: 947-955.

12. Jagetia GC, Reddy TK. Modulation of radiation induced alteration in the antioxidant status of mice by naringin. Life Sci 2005; 77: 780-794.

13. Al-Rejaie SS, Abuohashish HM, Al-Enazi MM, Al-Assaf $A H$, Parmar MY, Ahmed MM. Protective effect of naringenin on acetic acid-induced ulcerative colitis in rats. World J Gastroenterol 2013; 19: 5633-44.

14. Institute for Laboratory Animal Research: Guide for the Care and Use of Laboratory Animals. Eighth Edition, The National Academies Press, Washington, DC. 2011

15. Vogel GH. Drug Discovery and Evaluation: Pharmacological Assays. Springer-Verlag, Germany; pp. 2002; 324-325.

16. World Health Organization. Obesity and overweight. Geneva; 2006 (Access in 06/23/2009) Available from: http://who.int/mediacentre/factsheets/fs311/en/.

17. Dourmashkin JT, Chang GQ, Gayles EC, Hill JO, Fried SK, Julien C, Leibowitz SF. Different forms of obesity as 
a function of diet composition. International journal of obesity (Lond) 2005; 29(11): 1368-1378.

18. Schrauwen $P$, Westerterp KR. The role of high-fat diets and physical activity in the regulation of body weight. $\mathrm{Br}$ J Nutr 2000; 84(4): 417-427.

19. Tentolouris N, Pavlatos S, Kokkinos A, Perrea D, Pagoni $S$, Katsilambros $N$. Diet-induced thermogenesis and substrate oxidation are not different between lean and obese women after two different isocaloric meals, one rich in protein and one rich in fat. Metabolism 2008; 57(3): 313-320.

20. Daneshgari F, Liu G, Birder L, Hanna-Mitchell AT, Chacko S. Diabetic bladder dysfunction: current translational knowledge. J Urol 2009; 182: S18-S26.

21. Gasbarro G, Lin DL, Vurbic D, Quisno A, Kinley $B$, Daneshgari F, Damaser MS. Voiding function in obese and type 2 diabetic female rats. Am J Physiol - Renal Physiol 2010; 298: F72-F77.
22. Pu P, Gao DM, Mohamed S, Chen J, Zhang J, Zhou XY, Zhou NJ, Xie J, Jiang H. Naringin ameliorates metabolic syndrome by activating AMP-activated protein kinase in mice fed a high-fat diet. Arch Biochem Biophys 2012; 518: 61-70.

23. Ashakumari L, Vijayammal PL. Additive effect of alcohol and nicotine on lipid metabolism in rats. Indian J Exp Biol 1993; 31: 270-274.

24. Jayachitra J, Nalini N. Effect of naringenin (citrus flavanone) on lipid Profile in ethanol-induced toxicity in rats. J Food Biochem 2012; 36; 502-511.

25. Abdala S, Martin-Herrera D, Benjumea D, Perez-Paz P. Diuretic Activity of Smilax canariensis, An Endemic Canary Island Species. J Ethnopharmacol 2008; 119: 12-16

26. Cheung BMY, Ho SPC, Cheung AHK, Lau CP. Diastolic blood pressure is related to urinary sodium excretion in hypertensive Chinese patients. Q J Med 2000; 93 (3): 163-168. 